\title{
Editorial
}

\section{Naming the parts}

Giving names to geographical features has always been a contentious activity. In the days of the Jearly explorers everywhere in the world was apparently unnamed so royalty, expedition sponsors, senior politicians, wives and even children were liberally spread across the globe. Never mind if some of the countries already had native people who had their own names for the features our European explorers and colonisers knew better!

But no such problems existed in the Antarctic. As Terra Nullis with no population there could be no existing names, so first the explorers and later the surveyors and scientists felt free to name everything in sight. That should have made things easy for everyone, especially if the first name given was adopted by everyone - but that was far too simple. Political objectives, as usual, overcame common sense and the competing claimant countries were the first to see that providing names was a governance activity, whilst some of the non-claimant countries simply ignored the names already given for mountains, valleys and capes and provided new ones to recognise their own valiant Antarctic heroes. Thus developed the confusion that is now recorded in the Composite Gazetteer of Antarctica.

There are some perfectly reasonable explanations for some of the problems. In part this is because of the need to use a wide range of languages for maps produced in different countries. In some cases the feature is named after a person and so remains the same and is simply expressed in the other languages - for instance Hamilton Point as Cabo Hamilton. In other cases the name is descriptive and so is translated into the other language - for instance Half Moon Island and Isla Media Luna. However, there are now many instances of competing names for the same place - for instance the Argentine Isla Apendice is the same as the Chilean Isla Rivera and the British Sterneck Island.

The Treaty Parties could not find a compromise approach amongst themselves, instead issuing their own maps and gazetteers to promulgate their own names. Those who actually worked in the Antarctic, the poor scientists and logistics people, were left to deal with the chaos that resulted.

SCAR's initiative in establishing the Composite Gazetteer of Antarctica was the most important practical step in resolving this continuing muddle. Beginning in 1992 it initially digitised data in all the published gazetteers, providing the functionality that everyone needed without prejudice to any country's position. It currently contains just under 36000 names that correspond to over 18000 features, each feature being given a unique database identifier allotted to it by SCAR. By listing all the available names, without any judgements on which should be used, the Gazetteer attempts to provide an up-to-date and comprehensive listing, available to everyone via the Web and at no cost to the Parties. Now hosted by the Australian Antarctic Division, the enormous efforts put into this by the Italian programme, and especially Roberto Cervallati and Maria Chiara Ramorino, should be more widely recognised. Most recently SCAR has developed its usefulness by linking it to the map catalogue and to the biology databases.

Increasing co-operation between the existing national naming committees has helped to prevent duplication and more confusion. With 29 Consultative Parties you might expect there to be 29 responsible government organisations - but no such luck. Is it really too much trouble for every Party to nominate an official contact point for names so that in future consultation might improve, confusion might be reduced and SCAR might stand a reasonable chance of keeping order, at least for the scientists, in this problematic field?

DAVID W.H. WALTON 